\title{
Chapter 39 \\ Developing a Robust System \\ for Upskilling and Reskilling \\ the Workforce: Lessons \\ from the SkillsFuture Movement \\ in Singapore
}

\author{
Michael Fung
}

\section{The Fourth Industrial Revolution}

The impact of the Fourth Industrial Revolution on economies, jobs, and skills, heightened by the exponential rate of change, is considerable. With digitalisation, we are seeing significant shifts in job roles and the corresponding skills required. A large part of our work today will likely be automated, leading to a decline in jobs in some areas, job growth in other areas, and substantive changes to many job roles.

In the future of work, the shelf life of skills is anticipated to decrease to five years, with individuals expected to update and refresh their skills six times throughout their 30-year careers to remain relevant at their workplace (Deloitte 2017). In Singapore, an aging population exacerbated by a shrinking workforce (DOS 2017) creates an even sharper need for individuals to remain employable for a longer period of their lives. This means that employability will depend more heavily on lifelong learning and skills development, and less on initial qualification (ManpowerGroup 2018).

Singapore's Minister for Education Ong Ye Kung said, "The entire education experience is changing because of the emphasis on experience and skills. Industries will now support a more skills-based model to ensure that young people stepping out of education institutions can contribute almost immediately. Hence, education and industry will be drawn closer together in the coming years, and industries will play an increasingly bigger role in education and training" (Singapore Ministry of Education 2019).

\footnotetext{
M. Fung ( $\varangle)$

SkillsFuture Singapore Agency, Singapore, Singapore e-mail: Michael_FUNG@ssg.gov.sg 


\section{Implications of the Fourth Industrial Revolution for Education and Training Systems}

Education models in most countries, including Singapore, are still predominantly classroom-centric and institution-centric. Traditional, front-loaded education and training systems cannot fully prepare young adults for the jobs and skills required for the future (WEF 2017). To respond effectively to these new developments, education and training systems should shift towards a continual learning system for the workforce (Bughin et al. 2018).

SkillsFuture Singapore (SSG) works closely with stakeholders such as government agencies, institutes of higher learning (IHLs), and employers to ensure that skills training and upgrading for individuals continue to be readily accessible throughout their lives even as they move out of the school environment into the workplace. The IHLs together with employers and private training providers, form the three key pillars in our adult training and education landscape. In particular, the IHLs have evolved to play an increasing role in continuing education and training (CET). Traditionally focused on pre-employment training (PET) and education, the IHLs are now major providers of CET and promoters of lifelong learning, to ensure a tight nexus between learners' PET and CET throughout their lives. The National University of Singapore has moved to a model of " $4+20$ " for its undergraduate education, whereby students graduating with a 4-year bachelor's degree can come back to the university for the subsequent 20 years to upskill themselves.

The IHLs are progressively incorporating more workplace learning components in their programme offerings. For example, the SkillsFuture Work-Study Programmes, introduced in 2015, is a work-study system that moves away from a model of classroom learning to one that involves industrial practice as an integral part of the curriculum. The system comprises the Work-Study Diploma (run by the Institute of Technical Education), Work-Study Post-Diploma (previously known as the SkillsFuture Earn and Learn), and Work-Study Degree run by the universities. There are some parallels between the Work-Study system and successful apprenticeship models in Germany and Switzerland. The intention is to scale up the range and intake of such programmes such that it becomes a mainstream pathway in our education and training system.

For working adults, the IHLs take the lead in offering the SkillsFuture Series courses across eight emerging and priority skills domains: data analytics, finance, tech-enabled services, digital media, cybersecurity, entrepreneurship, advanced manufacturing, and urban solutions. These short, modular courses focus on emerging skills and are available in three levels_-basic, intermediate, and advanced-catering to learners with different skills proficiencies. Individuals can continually sharpen their existing skills and build new ones to stay relevant at work. By the end of 2018, more than 30,000 Singaporeans had attended courses in the SkillsFuture Series (SSG 2019).

To raise the quality of training and adult education, SSG introduced the Training and Adult Education Sector Transformation Plan (TAESTP) in 2016. The TAESTP 
identifies focal areas and recommendations to deliver CET training for the training and adult education sector. Initiatives such as the Education Industry Transformation Map and the Skills Framework for Training and Adult Education have been introduced to uplift the sector. As the education sector continues to transform, it is vital for individuals to achieve a spirit of lifelong learning and keep pace with the changing skills needs of the economy.

\section{The SkillsFuture Movement}

The SkillsFuture movement was launched in 2014 as a national skills strategy to help build the foundation for a highly skilled, productive, and innovative economy. Besides serving an economic objective, the SkillsFuture movement also seeks to help individuals realise their full potential, regardless of their starting points, enabling them to pursue their careers and interests. Various SkillsFuture initiatives have been introduced to target three groups of stakeholders, namely individuals, employers, and education and training institutions.

\section{Individuals}

Singaporeans can tap on SkillsFuture initiatives from as early as Primary 5 at the age of 11 years. For instance, the MySkillsFuture portal allows individuals to discover their interests through tools such as online self-assessment and games to help them understand the different industry sectors. The portal also allows them to explore education and training opportunities, and search for job openings across various industries.

In higher education, the SkillsFuture Work-Study programmes offer opportunities for students to learn through meaningful work assignments and industry exposure. The Work-Study Post-Diploma places fresh school leavers from vocational/technical tracks in salaried jobs while undergoing structured on-the-job training that lead to industry-recognised certifications. Some IHLs also offer overseas entrepreneurship programmes where students are attached to start-ups and tech companies in countries such as the People's Republic of China, India, United States, and Europe, to equip them with knowledge and appreciation of work cultures in different countries. These efforts by the education institutions ensure tighter coherence between education and work.

Beyond the schooling years, SSG ensures that learning continues to be accessible. All Singaporeans (aged 25 and above) are given a SkillsFuture Credit of SGD500, which can be used for some 20,000 courses on the MySkillsFuture portal. They can attend complimentary SkillsFuture Advice workshops to find out more about SkillsFuture initiatives and grants that can support their learning plans. Singaporeans in the workforce who wish to deepen their skills can apply for SkillsFuture Study 
Awards or SkillsFuture Fellowships, which provide monetary awards to defray their out-of-pocket training expenses.

\section{Employers}

Companies and industry players (including trade associations and professional bodies) help identify skills gaps and shape the development of the SkillsFuture initiatives. At the industry level, employers participate in the development of Industry Transformation Maps and Skills Frameworks, which provide key information on various sectors, corresponding skills required for the occupations and job roles, and relevant training programmes. Employers also play a key role in employee training. They can leverage initiatives such as the Enhanced Training Support for small and medium-sized enterprises (SMEs), and participate in a range of Work-Study programmes to address their talent needs.

Exemplary employers that champion skills development are recognised through the SkillsFuture Employer Awards. The National Centre of Excellence for Workplace Learning was launched in 2018 to help employers enhance their workplace learning capabilities and develop in-house training systems. SMEs looking to expand their business overseas can also tap on the Internationalisation Talent (iTalent) Solutions Map and Internationalisation Skills (iSkills) Talent Development Programme to build their capabilities and skills.

\section{Education and Training Institutions}

SSG supports education and training institutions in their transformation of course delivery to ensure learning becomes even more flexible and accessible. A strong pool of private training providers, including publicly funded CET centers, exists to support upskilling and industry transformation. The CET centers offer a comprehensive array of courses that cover a wide range of industries, and provide additional services, such as employment advisory and placement. Additionally, there are capability development grants and technological support under the iNnovative Learning 2020 (or iN.LEARN 2020) initiative to support institutions on curricular and pedagogical innovation that facilitates learning beyond classrooms.

\section{Critical Success Factors for the SkillsFuture Movement}

Since the launch of the SkillsFuture movement, more than 465,000 Singaporeans and 12,000 enterprises benefited from training subsidies in 2018. In the same year, over 3,500 people participated in SkillsFuture Work-Study programmes, while over 52,000 individuals attended workshops run by SkillsFuture Advice (SkillsFuture Singapore 2019). With the wide range of SkillsFuture initiatives, it is important to track training outcomes and the effectiveness of training. At the national level, the training participation rate of Singaporeans in 2018 was at 48\% (MOM 2018). SSG also conducts regular surveys of individuals and companies that have participated in the Singapore Workforce Skills Qualifications training. According to the survey, 8 
in 10 Singaporeans who attended SkillsFuture-funded courses last year found that their training helped them in their work (Straits Times 2019).

The two critical success factors of the movement are (i) the broad-based promotion of skills and literacy, and (ii) the cross-collaboration efforts among multiple agencies such as government bodies, IHLs, unions, and employers.

\section{Broad-based Promotion of Skills and Digital Literacy}

As technology continues to change the way companies operate, it becomes even more critical to build digital capabilities in workers across all major industry sectors to support business digital transformation. Adopting new technology alone is not adequate if workers are not trained to optimise the use of these tools. Recognising this, SSG launched the SkillsFuture for Digital Workplace courses to equip employees with foundational digital skills and help build their digital confidence. For example, the National Taxi Association and ComfortDelGro Taxi Company have trained close to 10,000 taxi drivers to pick up essential digital skills such as using e-payment applications. Another initiative is the SkillsFuture Series, where the short modular courses in data analytics and tech-enabled services have proven to be particularly popular.

\section{Multi-agency Efforts}

Cross-collaboration with multiple agencies, involving government agencies, industry bodies, unions, enterprises, and education and training providers, is crucial for the success of the SkillsFuture movement. One example is the development of the Skills Framework. An integral component of the Industry Transformation Maps, the Skills Framework provides key information on career pathways, emerging skills required, and a list of training programmes for skills upgrading. To date, over 30 Skills Frameworks have been rolled out for sectors such as aerospace, electronics, and financial services. Another example of a multi-party effort is the Systems, Applications and Products (SAP) Skills University Singapore, an effort among the German multinational software company SAP, SSG, and five polytechnics in Singapore to equip the workforce with critical skillsets in emerging technologies like artificial intelligence, data analytics, and the internet of things.

\section{Conclusion}

Education and training systems need to be even more agile and innovative than before to keep pace with the accelerating rate of change. To do so, training needs to be delivered in different modes, and in a timely manner to ensure relevance to the varying needs of learners. Learning also needs to evolve from a linear model to a flexible, adaptive, and lifelong model. The SkillsFuture Movement represents a major effort by Singapore to shift the education and training system to address the shortening shelf life of skills fueled by the Fourth Industrial Revolution. However, a truly effective lifelong learning system cannot be delivered by the public sector 
alone. A multi-stakeholder approach is required. Strong partnerships with education institutions, industry partners and employers are keys to success. Everyone needs to play a part in building up a responsive and effective skills ecosystem to establish a highly skilled workforce, in the spirit of lifelong learning.

Links to the presentation materials: https://events.development.asia/learning-events/ casestudy-singapore-s-skillsfuture-movement.

\section{References}

Bughin, J., Hazan, E., Lund, S., Dahlstrom, P., Wiesinger, A., \& Subramaniam, A. (2018). Skill shift: Automation and the future of the workforce. McKinsey Global Institute. https://www.mckinsey.com/featured-insights/future-of-organizations-and-work/skill-shiftautomation-and-the-future-of-the-workforce. Accessed 3 Aug 2018.

Deloitte. (2017). Forces of change: The future of work. https://www2.deloitte.com/insights/us/en/ focus/technology-and-the-future-of-work/overview.html. Accessed 6 Aug 2018.

ManpowerGroup. (2018). Solving the talent shortage: Build, buy, borrow, and bridge. https://go. manpowergroup.com/talent-shortage-2018. Accessed 6 Aug 2018.

Ministry of Manpower (MOM). (2018). Labour Force Survey Findings. https://stats.mom.gov.sg/ iMAS_PdfLibrary/mrsd_2018LabourForce_survey_findings.pdf. Accessed 1 Oct 2019.

Singapore Department of Statistics. (2017). Population trends 2017. https://www.singstat.gov.sg/-/ media/files/publications/population/population2017.pdf. Accessed 14 August 2018.

Singapore Ministry of Education. (2019). Opening address by Mr Ong Ye Kung, Minister for Education, at the Work-Learn Carnival. https://www.moe.gov.sg/news/speeches/opening-address-bymr-ong-ye-kung-minister-for-education-at-the-work-learn-carnival. Accessed 30 Sep 2019.

SkillsFuture Singapore (SSG). (2019). SkillsFuture 2018 Year-In-Review. https://www.myskillsf uture.sg/content/portal/en/about/about-myskillsfuture/2019-press-releases/-11-2-2019-skillsfut ure-2018-year-in-review.html. Accessed 30 Sep 2019.

Straits Times. (2019). Most trainees find skills training useful for work: Poll. https://www.straitsti mes.com/business/most-trainees-find-skills-training-useful-for-work-poll. Accessed 1 Oct 2019.

World Economic Forum. (2017). Accelerating workforce reskilling for the fourth industrial revolution: An agenda for leaders to shape the future of education, gender, and work https://www.weforum.org/whitepapers/accelerating-workforce-reskilling-for-the-fou rth-industrial-revolution. Accessed 3 Aug 2018. 
The views expressed in this Chapter are those of the authors and do not necessarily reflect the views and policies of the Asian Development Bank (ADB) or its Board of Governors or the governments they represent.

ADB does not guarantee the accuracy of the data included in this Chapter and accepts no responsibility for any consequence of their use. The mention of specific companies or products of manufacturers does not imply that they are endorsed or recommended by ADB in preference to others of a similar nature that are not mentioned.

By making any designation of or reference to a particular territory or geographic area, or by using the term "country" in this Chapter, ADB does not intend to make any judgments as to the legal or other status of any territory or area.

This work is available under the Creative Commons Attribution 3.0 IGO license (CC BY 3.0 IGO) https://creativecommons.org/licenses/by/3.0/igo/. By using the content of this Chapter, you agree to be bound by the terms of this license. For attribution, translations, adaptations, and permissions, please read the provisions and terms of use at https://www.adb.org/terms-use\#openac cess.

This CC license does not apply to non-ADB copyright materials in this Chapter. If the material is attributed to another source, please contact the copyright owner or publisher of that source for permission to reproduce it. ADB cannot be held liable for any claims that arise as a result of your use of the material.

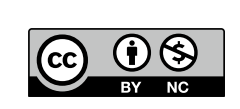

